\title{
A Contribuição de Karl Polanyi para a sociologia do desenvolvimento rural
}

SEREIO SCHNEIDER"

FABIANO ESCHER"

\section{Resumo}

O ensaio aborda a importância da redescoberta do pensamento de Karl Polanyi e de sua crítica à "sociedade de mercado" na retomada dos estudos e debates sobre o desenvolvimento (rural). Após uma apresentação geral do quadro teórico e analítico de Polanyi, buscamos utilizar seus conceitos para interpretar a dinâmica da mercantilização dos meios de vida e das formas sociais de trabalho e produção no espaço rural, bem como dos sistemas agroalimentares no capitalismo contemporâneo. Com base nestas proposições, refletimos sobre o papel dos atores sociais e das instituições nos processos de mudança social em geral e os de desenvolvimento rural em particular. Finalizamos, propondo algumas potencialidades dessa abordagem para os estudos sobre desenvolvimento rural no Brasil.

Palavras-chave: Karl Polanyi. Mercantilização. Instituições. Atores sociais. Desenvolvimento rural.

\footnotetext{
* Sociólogo, Mestre e Doutor em Sociologia e Professor do Programa de Pós-Graduação em Sociologia (PPGS) e Desenvolvimento Rural (PGDR) da Universidade Federal do Rio Grande do Sul (UFRGS). E-mail: schneide@ufrgs.br

** Economista, mestrando no Programa de Pós-Graduação em Desenvolvimento Rural (PGDR) da Universidade Federal do Rio Grande do Sul (UFRGS). E-mail: escher_fab@hotmail.com
} 


\section{Introdução}

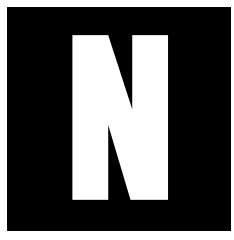

este início de século XXI, o tema do desenvolvimento voltou a ocupar espaço nas agendas de pesquisa dos cientistas sociais e a atrair considerável atenção dos formuladores de políticas. São várias as raízes desse interesse pelo tema. Inicialmente, vale lembrar que a retomada do interesse pelo desenvolvimento está relacionada aos efeitos de alguns eventos econômicos, sociais e políticos de grande alcance, ocorridos no último quarto do século passado. Entre estes, está o fim da guerra fria, o esgotamento dos modelos econômicos inspirados no keynesianismo e nas políticas de welfare state, a queda do Muro de Berlim e o subsequente esgotamento do regime estatista conhecido como "socialismo real". $\mathrm{O}$ atual esgotamento relativo da ideologia e das políticas neoliberais também inspira este interesse pela retomada do desenvolvimento. ${ }^{1}$ De certa forma, é possível sustentar que a partir do final dos anos 1990, aqui e acolá, surgem reações, críticas e contestações às promessas não cumpridas pelo neoliberalismo (Chang, 2009; Dupas, 2006; Harvey, 2005; Stiglitz, 2002).

Em contraponto a estes eventos e crises, estudiosos, instituições e policy makers passaram a indicar a necessidade de retomar alguns dos

1 Os governos de Reagan nos EUA e de Thatcher na Inglaterra, bem como as resoluções definidas no chamado "Consenso de Washington" representam marcos históricos para o "neoliberalismo" (HARVEY, 2005). As principais instituições e políticas neoliberais são: (i) o dólar como moeda internacional e o Federal Reserve Bank dos EUA como gerenciador do sistema monetário internacional; (ii) a expansão do comércio internacional sob a tutela do FMI, Banco Mundial e OMC; (iii) as privatizações e a liberalização dos mercados nacionais; (iv) a adoção de estratégias nacionais baseadas na abertura da conta capital e no crescimento com poupança externa; (v) a hegemonia do poder Norte Americano sobre o sistema mundial. Partindo dessas premissas os países ricos buscaram induzir os países em desenvolvimento a adotar uma agenda de reformas econômicas assentada na redução da intervenção do Estado, na manutenção da taxas de juros altas, no câmbio flexível, no equilíbrio fiscal e nas medidas de "ajuste estrutural" (BRESSER-PEREIRA, 2006; CHANG, 2009). 
velhos ensinamentos sobre o lugar do planejamento e o papel do Estado nos processos de desenvolvimento. Mas este momento difere significativamente do desenvolvimentismo das décadas de 1950 e 1960 (BresserPereira, 2006). Há algo de novo, que se refere, entre outras características e aspectos, ao consenso em torno da importância do papel das organizações e dos atores da sociedade civil na regulação dos mercados e do próprio Estado (Jessop, 2007). Isto ocorre, por exemplo, em relação aos temas ligados à questão ambiental e à sustentabilidade (Almeida \& Navarro, 2009) ou àqueles ligados à crise financeira e econômica mundial, que tem suas raízes na desregulamentação das finanças globais, devida largamente à ausência de regulação do Estado e à conduta especulativa dos agentes que atuam nos mercados financeiros (Associação Keynesiana Brasileira, 2008, 2010). É sabido e reconhecido que se trata de problemas cujas soluções passam pela presença direta e proativa do Estado, mas também é igualmente consensual que as organizações não governamentais e os atores da sociedade civil organizada, assim como o próprio setor privado, não podem ser deixados de fora dos processos de discussão, decisão e execução de medidas práticas.

É neste contexto que volta à cena o debate sobre o desenvolvimento, não sem adjetivações e qualificações que muitas vezes pouco ajudam em seu entendimento (Rist, 2007). Entretanto, mais importante do que achar adjetivos para ressignificar o desenvolvimento, a questão fundamental reside em saber qual seu conteúdo e quais são seus sentidos; ou seja, o que ele traz como proposta e a quem está endereçado. Para o cientista político Alan Thomas (2005, p.777), no contexto contemporâneo do capitalismo globalizado, é possível distinguir três sentidos interconectados do termo desenvolvimento: (1) como uma visão, descrição ou medida do que deve ser a sociedade desejada; (2) como um processo histórico de mudança social em que as sociedades são transformadas 
no decorrer de longos períodos; (3) como práticas e esforços deliberados que visam à promoção de melhorias, partindo de diversos atores sociais e de agências, incluindo governos, todos os tipos de organizações e movimentos sociais. Em suma, o desenvolvimento é uma construção social legitimada no campo político-ideológico como algo supostamente positivo, cuja arbitrariedade intrínseca é historicamente significada pelos atores sociais. Assim sendo, além de desvendar os processos econômicos, sociais e políticos por detrás da arbitrariedade inerente à idéia positiva de desenvolvimento, importa mostrar a quem se dirige e quem se beneficia deste discurso interpretativo (Escobar, 2000).

Neste sentido, é possível afirmar que existe um relativo consenso entre economistas e cientistas sociais de que o tema do desenvolvimento mobiliza as agendas de pesquisa em diferentes "blocos" de pensamento. Há os que argumentam que o livre-mercado, representado pela ideologia neoliberal, é incapaz de resolver os problemas do não-desenvolvimento, quais sejam, a desigualdade, a pobreza e a fome, a questão ambiental e os desafios da sustentabilidade, a crise financeira, a recessão econômica e o desemprego, etc. Há também os que argumentam que, através de "boas instituições", as organizações da sociedade civil podem exercer um papel propositivo e regulador na correção das falhas de mercado, via geração de confiança e de capital social, redução de custos de transação e ambiente favorável à inovação. Porém, também é possível se argumentar que, através da organização contra-hegemônica articulada em diversos níveis (social, político, econômico) e escalas (do local ao global), bem como da ativação e enraizamento de instituições democráticas, os próprios atores sociais podem estabelecer mecanismos de regulação e controle - tanto do risco da exacerbação do mercado (a ideologia neoliberal) quanto do poder do Estado (o autoritarismo) - capazes de promover processos de mudança social, democratização econômica e transformação estrutural das sociedades. 
Assim posto, o debate atual sobre o desenvolvimento recupera a agenda de questões formuladas por Karl Polanyi durante e após a segunda guerra mundial. $\mathrm{O}$ que revela a atualidade e a importância da redescoberta de seu pensamento. A esperança de Polanyi em uma transformação política radical não se confirmou, na medida em que, num "duplo movimento", o liberalismo foi apenas remediado com doses de intervenção estatal sem que, contudo, o sistema de mercados tenha deixado de ser o centro gravitacional da economia política mundial nos "30 anos gloriosos" (Lacher, 2007). Todavia, seus insights e muitos de seus conceitos mantêm-se atuais para uma crítica à teoria econômica mainstream e às instituições de uma sociedade cuja economia é (des) regulada por um sistema globalizado de mercados.

A principal obra de Polanyi, A Grande Transformação, foi publicada em 1944, mesmo ano da publicação de O Caminho da Servidão, de Friedrich Hayek, e oferece uma poderosa análise institucional da "utopia liberal" do século XIX. Ambos os livros tratavam da busca por relações simbióticas entre as esferas política e econômica a fim de obter a liberdade na vida em sociedade. Contudo, a análise histórica e o diagnóstico encontrados nas duas obras parecem ser polarmente opostos (Sachs, 1992). Enquanto, para Hayek (1987), o sistema capitalista de "livre-mercado" seria o único sistema social compatível com a prosperidade econômica, a dignidade humana e a liberdade pessoal, para Polanyi (2000), este sistema seria justamente a causa da alienação dos seres humanos e de sua natureza externa, da sua subordinação a uma racionalidade individualista, da instituição de valores predominantemente mercantis (como o consumismo), da reificação das relações humanas e da própria desumanização da sociedade. Mais do que gerar instabilidade econômica, o sistema capitalista de produção e a interação social via intercâmbio mercantil seriam responsáveis pela própria degeneração moral e crise sociocultural 
da humanidade. A subordinação da sociedade humana e a sua alienação à "lógica do mercado" - minando a capacidade de moldar a economia de acordo com os objetivos sociais por meio da política - constituem o problema central para a perspectiva Polanyiana. O seu pensamento embasa uma crítica consistente ao fundamentalismo de mercado e aponta para a necessidade da construção de instituições democráticas que tenham a "sociedade ativa" como categoria fundante (Burawoy, 2003).

Por esta razão, consideramos que as proposições centrais de Polanyi continuam oportunas e pertinentes à discussão e análise das principais questões debatidas no âmbito dos estudos sobre desenvolvimento em geral e desenvolvimento rural em particular. Primeiro, porque suas idéias expressam a importância central da regulação social sobre a economia e do papel das instituições, enquanto instâncias mediadoras entre as estruturas socioeconômicas e os indivíduos, como atores sociais. Segundo, porque, no contexto atual, a hipótese de que as empresas transnacionais e suas articulações de expansão constituem a força hegemônica no controle dos sistemas agroalimentares e representam o equivalente ao "moinho satânico" do capitalismo "auto-regulado" e destrutivo descrito por Polanyi é retomada na ideia de que as mesmas operam como verdadeiros "Impérios Alimentares". ${ }^{2}$ Por fim, porque no meio rural, especialmente do Brasil (mas não só) existe uma miríade de formas de ordenamento e interação social e econômica, assentadas sobre princípios estudados por Polanyi, como a reciprocidade e a redistribuição, e em geral subalternas e pouco conhecidas, que representam a base a partir da qual se poderia constituir uma "outra" forma de desenvolvimento rural.

\footnotetext{
2 Ploeg (2008) utiliza a noção de Impérios Alimentares como um dispositivo heurístico para caracterizar a nova "superestrutura" dos mercados globais. Trata-se de um modo de ordenamento que reorganiza progressivamente grandes domínios do mundo social e do mundo natural, sujeitando-os a formas institucionalizadas de controle na governança, apropriação e expansão dos fluxos de capital envolvidos na produção e distribuição agroalimentar.
} 
Mas, quando nos referimos à dimensão rural do desenvolvimento, também referimo-nos a um recorte metodológico, na medida em que o interesse da análise é compreender os processos de mudança social que ocorrem no espaço rural, sem desconsiderar suas interfaces com as outras dimensões. Segundo essa percepção, o desenvolvimento rural diz respeito tanto aos processos e ações que influem na melhoria das condições objetivas de reprodução social das populações rurais quanto às relações das populações e do espaço rural com os demais processos de mudança econômico-ambiental, técnico-tecnológico, sócio-cultural, político-institucional, ético-moral, em uma gama mais ampla de relações com toda a sociedade (Bebbington, 2001; Schneider, 2010). Neste sentido, entendemos o desenvolvimento rural enquanto um "processo instituído" por meio de "contramovimentos" dos atores sociais no contexto das contradições características do capitalismo contemporâneo.

O objetivo principal deste ensaio é fazer um resgate dos conceitos e formulações centrais presentes na obra de Karl Polanyi, cotejando-os com a realidade atual. Nossa pretensão consiste em mostrar que o arcabouço analítico (framework) de Polanyi é adequado para o estudo de alguns processos e questões relacionadas ao desenvolvimento rural, tais como: a mercantilização dos meios de vida e sua interface com aquilo que Ploeg (2009) chama de "Impérios Alimentares"; a natureza dos mercados e sua relação com a noção de embeddedness; a coexistência das três "formas de integração" nas sociedades capitalistas contemporâneas e sua relação com o papel do Estado e das políticas públicas; o papel dos atores da sociedade civil e das instituições nos processos de mudança social.

O texto está estruturado em cinco seções, além dessa introdução. Na segunda seção, fazemos uma apresentação do quadro teórico e analítico de Karl Polanyi. Na terceira seção, problematizamos as transformações decorrentes da mercantilização da agricultura, do espaço rural e dos 
sistemas agroalimentares. Na quarta seção, refletimos sobre o papel dos atores sociais no desenvolvimento rural, compreendendo-o como um "processo instituído" de mudança social. Por fim, na quinta seção, fazemos algumas considerações finais.

\section{O quadro teórico da "análise institucional" de Karl Polanyi}

Karl Polanyi (Áustria, 1886 - Canadá, 1964) pode ser considerado um dos grandes pensadores do século XX, mas é um autor ainda pouco conhecido no Brasil, não obstante o crescimento considerável do interesse pela sua obra. Pode-se dizer que, talvez, o período mais importante da vida acadêmica de Polanyi tenha se passado nos Estados Unidos e no Canadá, enquanto trabalhou na Universidade de Columbia. O que, todavia, não desautoriza afirmar que ele seja um dos mais importantes autores ligados a tradição institucionalista européia. Mas também é verdade que seu pensamento converge sobremaneira com o institucionalismo norte-americano, cuja referência principal é Thorstein B. Veblen (Machado, 2009).

Por causa deste relativo desconhecimento e deste crescente interesse, buscamos resumir as principais contribuições teóricas de Karl Polanyi (1976, 1977a, 1977b, 2000) nesta seção. O conteúdo das reflexões expostas em sua obra pode ser agrupado em duas frentes. A primeira propõe explicar as mudanças nas estruturas institucionais e no imaginário social, a partir do século XIX, que resultam na relativa desvinculação e autonomização (disembeddedness) da esfera econômica frente à esfera política e no processo de formação e crise da "sociedade de mercado". Este é o tema do seu livro The Great Transformation, de 1944. A segunda apresenta uma interpretação histórica e antropológica do desenvolvimento das economias nas sociedades "primitivas, arcaicas e modernas". Este é o tema em especial da obra conjunta Trade and markets in early empires, de 1957. Nestas obras, Polanyi 
e seus colaboradores lançam mão de um ferramental interdisciplinar para pôr em evidência as condições institucionais de produção, circulação e repartição dos bens nessas diferentes sociedades e períodos históricos. "Daí a utilização frequente do termo 'análise institucional' para designar seu empreendimento." (Maucourant, 2005, p.15; tradução nossa).

Segundo Sanchéz (2008), a obra de Polanyi constitui uma crítica epistemológica e ontológica dos fundamentos do pensamento econômico clássico e neoclássico, e seu método de análise institucional permitiu-lhe considerar a esfera econômica como parte da totalidade social, cultural e política em que se inscreve historicamente. Deste modo, Polanyi conseguiu rastrear "a construção histórica da economia de mercado como um imenso e violento processo social artificial, que não obedeceu às supostas características da natureza humana, mas uma aposta ideológica, axiológica e política radicalmente diferente das formas anteriores em que os grupos humanos haviam organizado e integrado os recursos materiais e seu sustento." (Sanchéz, 2008, p.1; tradução nossa).

\section{A "falácia economicista" e os dois significados da economia}

A força da crítica de Polanyi à teoria econômica ortodoxa e ao liberalismo econômico reside justamente no fato de que sua análise mantém a história econômica ligada à história das idéias sobre economia. O que ele chama de "falácia economicista" refere-se à estreiteza da concepção filosófica e ao limite dos princípios metodológicos da teoria econômica ortodoxa - construída sobre axiomas irrealistas, que não correspondem aos processos substantivos da economia humana - a qual identifica o conteúdo da noção de economia com o da noção de mercado. ${ }^{3} \mathrm{~A}$ partir de certos postulados

3 Uma crítica aos princípios metodológicos da economia neoclássica pode ser encontrada em Arnsperger \& Varoufakis (2006). E para uma análise da crítica de Polanyi à economia ortodoxa convencional, bem como dos próprios limites de sua abordagem para uma teoria da economia política, ver Lopes (1971). 
axiomáticos, a economia é definida como a ciência cujo objeto é a alocação eficiente de recursos escassos objetivando a maximização da utilidade individual - a "otimização". Para a teoria, é como se a economia humana em geral fosse equalizada a uma única forma, qual seja, o "mercado", o lugar de encontro entre "oferta e demanda", onde se formam os "preços de equilíbrio". Uma interpretação idealista e equivocada, na medida em que a economia é um processo dinâmico e histórico e não uma sucessão de situações de equilíbrios agrupadas por meio de "estática comparativa".

Polanyi (1977b) explica que a mentalidade dos homens e sua própria racionalidade são informadas pelas instituições vigentes e que os mercados são complexos institucionais historicamente constituídos e, não, construtos teóricos abstratos, como pretende a teoria neoclássica. Explica também que os preços são produto do comércio - enquanto resultado da troca dos bens por uma expressão do poder de compra (dinheiro) - independente da existência de um sistema de mercados auto-regulado. Quer dizer, os preços existem, na medida em que existe troca entre os seres humanos em uma sociedade complexa, mas não necessariamente de maneira a constituir um sistema abstrato de "oferta-demanda-preços-equilíbrio". Ocorre que, com a mercantilização instituída de elementos substantivos da economia humana, cria-se um mecanismo de preços flutuantes, consubstanciando a apropriação do excedente como mera projeção do padrão de mercado na economia, na forma de remuneração dos "fatores de produção". Mas, a explicação para isso não deve ser buscada nas diferentes combinações de fatores em funções de produção ou no equilíbrio entre oferta e demanda, e sim nas relações sociais historicamente instituídas para garantir o sustento das coletividades humanas.

De modo a desmistificar a "falácia economicista" e a obsessão intelectual pelo mercado, Polanyi deu o pontapé inicial de um debate da 
antropologia econômica, entre formalistas e substantivistas, ao explicitar a distinção entre os dois significados da economia (Lopes, 1971; Molina, 2007). O primeiro significado, o "formal", que "deriva do caráter lógico da relação entre meios e fins", se refere à escolha racional entre usos alternativos de recursos escassos em busca de maximização. O segundo significado, o "substantivo", que "deriva da dependência em que se encontra o homem em relação à natureza e a seus semelhantes para conseguir seu sustento", se refere ao intercâmbio com o meio natural e social, através do qual os seres humanos conseguem satisfazer suas necessidades materiais.

O que acontece, segundo Polanyi (1976, 1977b), é que a economia convencional funde a noção de subsistência com a de escassez, incorrendo num equívoco metodológico. Pois, tal fusão só é possível em um caso específico e aistórico - o sistema teórico de "oferta-demanda-preços-equilíbrio". Mas, como a atividade econômica não se reduz ao caso formal da teoria neoclássica, apenas o significado substantivo da economia pode proporcionar às ciências sociais os conceitos adequados ao estudo de "todas as economias que existiram e existem", na medida em que se fundamenta nos fatos sociais e naturais empíricos, concretos, e não em abstrações, lógicas, mas destituídas de fundamento e de conteúdo histórico.

A economia como "processo instituído" e as "formas de integração"

Para Polanyi (1976; 1977b), a economia substantiva deve ser compreendida enquanto um processo instituído de interação entre os seres humanos, com o objetivo de satisfazer suas necessidades materiais, através dos meios de vida socialmente disponíveis. Assim, o processo econômico se dá em dois níveis: o da atividade interativa entre os seres humanos e seu entorno; e o da institucionalização deste processo. A atividade de interação econômica é, ao mesmo tempo, um fenômeno material e social. E, para a satisfação das necessidades humanas, os elementos ecológicos, tecnológicos e culturais podem mudar de posição, seja material- 
mente, através de movimentos situacionais (mudando de lugar ou de estado), seja socialmente, através de movimentos apropriacionais (mudando de "mãos" ou de propriedade). ${ }^{4}$ Os movimentos apropriacionais, por sua vez, dizem respeito às relações sociais de troca, distribuição e propriedade historicamente instituídas, ao passo que os movimentos situacionais dizem respeito às relações sociotécnicas de trabalho e produção. Quanto à institucionalização do processo econômico, Pearson (1977, p. xxxii. tradução nossa), um íntimo colaborador de Polanyi, assevera que:

A organização social do poder apropriacional é a chave para qualquer consideração da economia como um sistema social. Isso localiza a matriz institucional, que ordena as relações econômicas entre os homens, e define o lugar da economia na sociedade no sentido que localiza a fonte dos direitos e obrigações que sancionam os movimentos de bens e pessoas para, através e fora do processo econômico.

Para Polanyi, os modos de organização social do processo econômico - em suas palavras, as "formas de integração" - devem sua existência às interações culturalmente institucionalizadas por meio de específicas e correspondentes "estruturas de suporte". As principais formas empíricas trans-historicamente identificadas por Polanyi são três ${ }^{5}$ :

4 Segundo Polanyi, os movimentos situacionais implicam em deslocamento espacial (transporte) ou em transformação dos elementos materiais (produção). De acordo com a utilidade que tem para o consumidor, os produtos são classificados como: de ordem superior (bens de consumo), na medida em que satisfazem as necessidades de consumo direto; ou de ordem inferior (bens de produção), na medida em que satisfazem as necessidades de consumo indireto, intermediário, combinando-se com outros elementos no processo produtivo. Os movimentos apropriacionais, por sua vez, implicam nas relações entre os seres humanos na aquisição, administração e dotação dos bens de produção e de consumo, através de transações, tributações, direitos legais, convenções, etc.; e dependem das formas como a força de trabalho, o conhecimento e a tecnologia são postos em movimento no processo de produção e de como o produto dessa atividade é distribuído entre os membros da sociedade. (POLANYI, 1976, p.293-294; 1977b, p.31-32).

5 Polanyi também inclui uma quarta forma, contudo menos importante em sociedades complexas: Domesticidade e autarquia - pode ter características de todas as outras três formas, dentro de uma unidade autônoma de produção e consumo. Um exemplo seriam as economias/sociedades camponesas. 
(1) Reciprocidade e simetria: descreve os movimentos de bens e de serviços entre pontos correspondentes de um agrupamento simétrico. Ou seja, a disposição dos elementos e as sanções que determinam o uso produtivo e distributivo destes recursos derivam de normas comportamentais ou de expectativas impostas por sistemas não-econômicos, como os de parentesco, amizade, envolvimento associativo ou cooperação;

(2) redistribuição e centralidade: descreve o movimento de bens e serviços em direção a um centro e seu retorno aos consumidores, seja por meio de deslocamento físico ou apenas de disposição. Aí, os padrões de distribuição determinam os direitos e obrigações, localizados em um centro identificável, de onde os recursos serão redistribuídos, através de regras e mecanismos de controle, por alguma autoridade que ordena essa disposição. Estes padrões de organização econômica estão intrinsecamente ligados ao ordenamento político das sociedades. Os sistemas de tributação, impostos e taxação, organizados em diferentes instâncias administrativas dos Estados modernos, são exemplos de formas de integração redistributiva; (3) intercâmbio e mercado: descreve o movimento de bens e serviços entre diferentes, dispersos e aleatórios pontos no sistema. É um padrão transacional, caracterizado por motivos de autointeresse. Nesta forma de integração, onde o padrão de alocação dos recursos é o mercado, a característica essencial da troca diz respeito à maneira como são disponibilizados os direitos e as obrigações apropriacionais. A disposição é determinada pelos direitos de propriedade e pela relação com os meios materiais daí derivados; o sistema é sancionado pela relação de propriedade privada e pelo livre-contrato; e a distribuição é feita através de compra e venda, utilizando-se do mecanismo de preços e do dinheiro como expressão do poder de compra. 
Estas "formas de integração" institucionalizam-se por meio da socialização de práticas baseadas em dispositivos de ação coletiva e em sistemas de regras, como parte reguladora do ordenamento da vida social, econômica e política das pessoas, com seus valores e lógicas de operação específicas. Para Polanyi, são as instituições culturais de integração que moldam o comportamento "econômico" dos indivíduos numa sociedade complexa, e não tendências psicológico-comportamentais inatas, como as do homo oeconomicus neoclássico. As motivações que desencadeiam o comportamento econômico dos indivíduos só têm sentido dentro do ambiente institucional e das relações sociais em que eles estão inseridos. Então, para explicar a natureza da economia de mercado, Polanyi (2000) reconstrói os processos materiais e culturais que levaram ao seu surgimento como consequência da construção deliberada das instituições pelos seres humanos. Ao contrário de Hayek (1987), que acreditava na economia de mercado como resultado "não intencional e espontâneo" das interações individuais. Portanto, as diferentes formas de integração não só dão lugar a mobilização, produção e consumo de bens, como são também 'produtoras de sujeitos', ao ficarem cunhados nestes os comportamentos baseados nos valores contidos nas instituições que regulam a organização da ordem social. (Sanchéz, 2008, p.10; tradução nossa).

Capitalismo e "mercadorias fictícias": trabalho, terra e dinheiro

As formas de integração e suas estruturas institucionais de suporte são dependentes das relações sociais, da divisão do trabalho, das relações de propriedade, da separação entre consumidores e produtores e da forma de atuação do Estado. Elas constituem sistemas de troca e distribuição dos elementos materiais necessários à satisfação das necessidades humanas. Neste sentido, para Polanyi (2000), a economia de mercado é produto da sociedade industrial, na medida em que as instituições que regulamentaram e 
propiciaram o desenvolvimento industrial cresceram concomitantemente ao sistema de mercados. Na passagem a seguir, ele descreve o processo que pavimenta a emergência da economia de mercado.

O passo crucial foi o seguinte: trabalho e terra foram transformados em mercadorias, foram tratados como se tivessem sido produzidos para a venda. Evidentemente que, na realidade, não eram mercadorias, uma vez que não eram sequer produzidos (como a terra) ou, quando o eram, não o eram para a venda (como o trabalho). E, no entanto, nunca houve uma ficção tão completamente eficaz como esta. Com a compra e venda livre do trabalho e da terra, o mecanismo do mercado tornava-se aplicável a estes. Havia agora oferta e procura de trabalho; havia oferta e procura de terra. Havia, por conseguinte um preço de mercado para o uso da força de trabalho, chamado salário, e um preço de mercado para o uso da terra, chamado renda. Ao trabalho e à terra foram agora atribuídos mercados próprios, tal como acontecia com as mercadorias que eram produzidas por seu intermédio. $\mathrm{O}$ verdadeiro alcance de um tal passo pode ser entendido se nos lembrarmos que trabalho é apenas um outro nome para o homem e terra para a natureza. (Polanyi, 1977a, p. 9). Finalmente, o dinheiro é apenas um símbolo do poder de compra e, como regra, ele não é produzido, mas adquire vida através do mecanismo dos bancos e das finanças estatais. Nenhum deles é produzido para a venda. A descrição do trabalho, da terra e do dinheiro como mercadorias é inteiramente fictícia. (idem, 2000, p.94).

Segundo Polanyi, numa sociedade em que a economia substantiva é regulada por um sistema de mercados, não apenas os bens e serviços, mas as próprias pessoas (enquanto força de trabalho) e seus meios de vida são convertidos em mercadoria e sujeitos à precificação. Ou seja, são alienados na forma de mercadorias (fictícias) e, assim, podem ser comprados e vendidos a preços de mercado. Os preços em si existem, desde que existe troca e comércio, mas a crescente determinação dos preços pelos custos de produção e a apropriação do excedente através de compra e venda na 
busca do lucro apenas se desenvolvem completamente numa sociedade integrada por um sistema de mercados. Uma mercadoria fictícia não tem seu preço determinado pelo custo de produção, na medida em que não é uma mercadoria produzida, mas uma mercadoria instituída, através de mecanismos como a lei, o costume, a ideologia, ou mesmo a violência.

Assim sendo, o capitalismo pode ser conceituado como uma "sociedade de mercado", pois não apenas os produtos, mas a própria produção destes e a reprodução social dos indivíduos - que precisam vender sua força de trabalho para sobreviver - dependem de tal mecanismo. Para que a produção seja movida em uma sociedade cuja economia é regulada por um sistema de mercados, supõe-se que os meios de produção - incluindo a terra, o trabalho e o dinheiro - sejam mercadorias. Numa tal sociedade, a troca e a distribuição (circulação) tendem a ser estabelecidas por meio de igualdades formais entre oferta e demanda, dando origem aos preços nominais. Assim, a provisão dos meios de vida dos seres humanos torna-se dependente do mecanismo de mercado, submetendo a própria reprodução do tecido social à reprodução do capital. Reconhecido isto, podemos concluir que, no capitalismo, os motivos "econômicos" do comportamento social - entre eles a busca competitiva pelo ganho e o medo da fome por exclusão do mercado de trabalho - envolvem a crescente dominância das atividades "orientadas ao lucro" e "mediadas pelo mercado". ${ }^{6}$

"O problema do embeddedness": economia de mercado como projeto político

A análise da natureza das mercadorias fictícias nos permite a apreensão de um ponto central da contribuição teórica de Karl Polanyi - a

6 Apesar de tirarem diferentes conclusões e propostas de encaminhamento político, autores de correntes teóricas tão diversas como Jessop (2007) e Sen (2000), concordam com essa constatação. 
noção de embeddedness. ${ }^{7} \mathrm{O}$ termo não tem um correlato em português, portanto, ora usaremos 'imersão', ora 'enraizamento'. O conceito se refere à formação de significado para as ações dos atores inseridos num contexto ou ambiente institucional historicamente determinado, e expressa a ideia de que as estruturas sociais, estabelecidas e enraizadas em regras, normas, convenções, hábitos, etc. condicionam o comportamento social dos indivíduos. Para o autor, até a emergência da sociedade industrial regulada pela economia de mercado, o sistema econômico estava submerso em relações sociais gerais; os mercados eram apenas um aspecto acessório de uma estrutura institucional controlada e regulada, mais do que nunca, pela autoridade social (Polanyi, 2000, p. 88). Porém, com a expansão desse padrão societal de integração mercantil-capitalista, ocorre uma pretensa separação institucional das esferas econômica e política da sociedade.

Entretanto, isto não implica na existência de instituições econômicas separadas. Normalmente a ordem econômica é apenas uma função social, na qual ela está inserida. Um tal padrão institucional não poderia funcionar a menos que a sociedade fosse subordinada, de alguma forma, às suas exigências. Uma economia de mercado só pode existir numa sociedade de mercado. A extrema artificialidade da economia de mercado está enraizada no fato de o próprio processo de produção ser aqui gozado sob a forma de compra e venda. (2000, p. 92-95).

A partir da instituição do sistema de preços e da restrição monetária, a escassez estrutural é produzida e o medo da fome e a busca pelo

7 Desde a publicação do já clássico artigo de Granovetter (1985), o conceito de embeddedness tem sido amplamente utilizado e ressignificado, na maior parte das vezes de forma contraditória, pelos autores da Nova Sociologia Econômica (NSE). Apenas registrarmos nossa discordância às críticas que Granovetter (1985) dirige a Polanyi, pois na NSE o conceito de embeddedness é esvaziado do conteúdo eminentemente político que apresenta na obra deste autor. Em suma, o conceito não ocupa o mesmo lugar teórico e não possui o mesmo sentido nas diferentes abordagens. Para uma discussão pormenorizada ver Beckert (2007) e Machado (2009). 
lucro aparecem como motivos econômicos quase naturalizados. Assim, a economia formal é convertida em sociedade de mercado, desenraizando a economia substantiva das instituições sociais. Deste modo, segundo Polanyi (2000), em vez de a economia estar embutida nas relações sociais, são as relações sociais que estão incrustadas [embedded] no sistema econômico (p.77). Seguindo este raciocínio, a sociedade humana tornara-se um acessório do sistema econômico (p.97). Ou seja, a esfera econômica parece se desvincular e se autonomizar em relação à esfera social.

Contudo, para que os meios de produção tornem-se capital, devem estar enraizados em uma série de instituições - normas legais, regras e convenções sociais, organizações, costumes, hábitos mentais compartiIhados - que permitam sua utilização como forma de acumulação privada de riqueza por quem tem acesso aos mesmos. Assim, na perspectiva de Polanyi, a economia de mercado não é um fenômeno espontâneo e natural, mas um projeto político, realizado através da mudança institucional cuja dinâmica decorre do processo de mercantilização da terra, do trabaIho e do dinheiro. Portanto, para Polanyi, esta desvinculação e autonomização (disembeddedness) da economia são, ao mesmo tempo, uma realidade sociológica objetiva e um projeto político orientado por interesses de atores, grupos e classes sociais específicas. Projeto este concretizado por meio de mudanças institucionais, introduzidas através da violência e da ação legislativa, e legitimado através de uma ofensiva ideológica, na qual a teoria econômica ortodoxa assume papel crucial, ao contribuir para a criação de uma "crença liberal": a de que a economia não pode (e não deveria) ser modificada pelas práticas dos atores sociais, através da intervenção deliberada da sociedade ativa sobre os mercados valendo-se do Estado. Pois isto possibilitaria a emergência de processos de mudança social e de re-enraizamento, que não interessam ao projeto dessas classes dominantes (Bugra \& Agartan, 2007; Burawoy, 2003; Maucourant, 2005). 
O "duplo movimento": a dinâmica entre estado, mercados e sociedade

Para Polanyi (2000, p.93), mercantilizar o trabalho e a terra - que nada mais são do que os próprios seres humanos, dos quais consistem todas as sociedades, e o ambiente natural no qual elas existem - significa subordinar a substância da própria sociedade às leis do mercado. Da mesma forma, deixar a administração do poder de compra para o por parte do mercado liquidaria empresas periodicamente, pois as faltas e os excessos de dinheiro seriam tão desastrosos para os negócios como as enchentes e as secas nas sociedades primitivas. Este desenraizamento da economia substantiva em relação às instituições sociais e políticas, especialmente em relação ao Estado, faz parte da ordem instituída em uma sociedade de mercado.

Entretanto, nenhuma sociedade suportaria os efeitos de um tal sistema de grosseiras ficções, mesmo por um período de tempo muito curto, a menos que sua substância humana natural, assim como a organização de negócios, fosse protegida contra os assaltos desse moinho satânico.(...) Permitir que o mecanismo de mercado seja o único dirigente do destino dos seres humanos e do seu ambiente natural, e até mesmo o árbitro da quantidade e do uso do poder de compra, resultaria no desmoronamento da sociedade. (Polanyi, 2000, p.94).

A partir dessa conclusão, Polanyi (2000) identifica uma contradição interna fundamental do sistema de mercado como regulador das atividades econômicas da sociedade: um "duplo movimento". Por um lado, um movimento de expansão da sociabilidade capitalista, imprimido pela habituação ao intercâmbio mercantil, e, por outro, um contramovimento contestatório de autoproteção da sociedade contra os assaltos deste "moinho satânico".

O conceito de "duplo movimento" é introduzido na análise de Polanyi para apreender a dinâmica histórica do século XIX e das primeiras décadas do século XX. O "contramovimento" para a proteção da socie- 
dade, da natureza e da própria organização produtiva é vital para o desenvolvimento da economia humana, mas incompatível com o sistema autorregulado de mercados. Nas interpretações de Block (2003) e Bugra (2007), a tese Polanyiana é a de que uma "sociedade de mercado", objetivamente, não passa de uma ideologia, impossível de ser institucionalizada como uma realidade social sem destruir a atividade industrial, a natureza externa ao homem e a própria sociedade humana, com seus valores e sua cultura. Isto, porque a liberdade individual numa sociedade complexa só seria protegida pela intervenção política deliberada na vida social e econômica, pela ação dos atores sociais, através de inovações, adaptações e mudanças nas instituições vigentes.

Para Polanyi (2000), por um lado, o desenraizamento da economia, expresso na institucionalização das mercadorias fictícias, não é compatível com a sociabilidade humana; por outro, as ações legislativas tomadas para proteger o tecido social ou a natureza externa ao homem não são compatíveis com os princípios da economia de mercado. A constituição ontológica de uma sociedade cuja economia seja organizada sob um sistema auto-regulável de mercados é, então, impraticável, na medida em que a própria intervenção estatal, as restrições ao comércio e os instrumentos de regulação são manifestações dessa ontologia expressa nas políticas e nas instituições de uma sociedade em que opera uma economia de mercado.

Neste sentido, o conceito de "duplo movimento" possui uma importância heurística para a apreensão da atual dinâmica da relação entre Estado, Mercados e Sociedade Civil. Para autores como Bugra (2007), a crise do "welfare state" e a globalização da economia mundial cada vez mais têm diluído as responsabilidades redistributivas do Estado entre uma série de organizações não governamentais e entidades do setor privado. Segundo este autor, para Polanyi, os "contramovimentos" estavam diretamente ligados a medidas legislativas de proteção do tecido social, que deslocavam as mer- 
cadorias fictícias para fora da órbita do mecanismo de mercado. De maneira diversa, na atualidade, a liberalização, a privatização e a desregulamentação dos mercados financeiros, de trabalho, de terras, de alimentos, têm tido um papel central nas novas formas - ditas "flexíveis" - de acumulação de capital em escala global. É fato que, apesar de inumeráveis manifestações de resistência e contestação, estes valores continuam a ser hegemônicos e a produzirem consequências sociais desastrosas.

Contudo, apesar de estarmos vivenciando um período histórico diverso do analisado por Polanyi, seus insights e sua ontologia são elementos importantes para a análise dos complexos "regimes de governança" do atual capitalismo globalizado. A corrente dinâmica do duplo movimento é engendrada em meio a tensões envolvidas nas relações entre o Estado, com suas diversas instâncias administrativas, e as organizações da sociedade civil, os sindicatos, os movimentos sociais, as corporações capitalistas e conglomerados empresariais, em níveis que vão do local ao global, diante dos processos econômicos, sociais e políticos (Adaman \& Madra, 2002). Nas contradições desta dinâmica é que emergem as possibilidades e se manifestam os limites para a institucionalização de organizações, de regras e de práticas que rompam com a lógica (neoliberal) da economia mundial e que promovam a descentralização das estruturas de ação do Estado e a democratização econômica substantiva, com base na "sociedade ativa" (Burawoy, 2003).

\section{Os assaltos do "moinho satânico" nos campos e a expansão dos "Impérios Alimentares"}

A atualidade das reflexões de Polanyi, como referências para pensar as questões ligadas ao desenvolvimento na contemporaneidade, fica evidente com o exposto nas seções anteriores. Não obstante, em face 
das grandes transformações sociais ocorridas, a sua abordagem necessita de uma atualização e contextualização à realidade do século XXI. Neste sentido, a seguir argumenta-se que a "análise institucional" de Karl Polanyi é oportuna e pertinente para tratar dos processos de mudança social e desenvolvimento rural.

N'A Grande Transformação, Polanyi atentara sobremaneira para as mudanças sociais que ocorreram com os meios de vida das populações e com o espaço rural da Inglaterra em virtude da Revolução Industrial e do nascimento dos mercados de trabalho, de terras e de dinheiro. A terra, escreveu Polanyi (2000, p.214), é um elemento da natureza [...] entrelaçado com as instituições do homem... Tradicionalmente, a terra e o trabalho não são separados: o trabalho é parte da vida, a terra continua sendo parte da natureza, a vida e a natureza formam um todo articulado. Mas a instituição das mercadorias fictícias desencadeou processos sociais e políticos que tentaram desagregar as "formas orgânicas de existência", pavimentando o caminho da industrialização e subordinando o homem e a natureza à expansão da economia de mercado. Tomando o exemplo clássico da Inglaterra, Polanyi descreve o caso dos cerceamentos dos campos, bem como o estabelecimento de leis de proteção social, como a Speenhamland Law, instituída para impedir a morte em massa da população, por inanição. Posteriormente a Poor Law Reform aboliu o "direito de sobreviver" instituído pela Speenhamland Law, pavimentando a formação dos mercados de trabalho e de terras, bem como a transferência de recursos destinados aos pobres rurais para financiar o investimento industrial.

Através destas narrativas, Polanyi (2000) demonstra que os mercados de trabalho e de terra foram formados a partir da separação entre as condições objetivas de produção e seus produtores diretos, da expulsão dos camponeses das terras comunais e da instituição da propriedade privada. Deste modo, além da separação entre as atividades manuais 
e intelectuais dos produtores diretos, ocorre uma separação entre as atividades urbanas e rurais, gerando uma oposição fictícia entre campo e cidade. O que era anteriormente produzido com base em condições naturais, passa a ser produzido sob condições artificiais, fabricadas, adaptadas e subordinadas à expansão da economia de mercado. Assim, a agricultura passa a ser vista como mera fornecedora de matéria-prima para a indústria e de alimentos para a população urbana. Da mesma forma, o espaço rural é visto como um resíduo da urbanização (esta sim, signo da modernidade), como um lugar de atraso.

Com a mundialização do capitalismo, a subordinação da agricultura à indústria e aos mercados foi exacerbada ao longo de todo o século XX, e continua a sê-lo, enquanto um processo contínuo e inacabado (Goodman, Sorj e Wilkinson, 1990). Neste sentido, a mercantilização da agricultura ocorre por meio de disputas, entre frações do capital, o Estado e os agricultores, pelo controle dos recursos produtivos e, assim, pelo controle dos próprios mercados em que interagem (como de insumos, de trabalho, de produtos, de crédito, de terras, etc.). Então, podemos compreender a mercantilização da agricultura como um processo de "incorporação institucional" (Long, 2001), por meio da interação - não raramente conflituosa - entre os atores sociais, através de distintas "formas de integração".

A exemplo da chamada "modernização da agricultura", a mercantilização é institucionalizada por meio de um conjunto de processos interconectados. Primeiro, temos a "externalização" crescente das etapas do processo de produção, através da transferência do controle de tarefas, recursos e processos produtivos, até então exercido pelos próprios agricultores, para atores externos - de tal maneira que os processos não podem se reproduzir fora do alcance do capital. Cresce o número de tarefas que são separadas no processo de trabalho e passam a ser coordenadas exogenamente, através da multiplicação das relações 
de intercâmbio mercantil e por meio de um sistema de relações técnico-administrativo-informacionais. Assim, é gerada uma oposição entre trabalho mental e trabalho manual dos produtores diretos, alterando sua autonomia relativa e transformando as condições objetivas de sua reprodução socioeconômica. (Ploeg, 1992).

Dois outros processos vêm a reboque da externalização, complementando a mercantilização da agricultura. Um é a "cientifização" dos processos de produção, através da incorporação de tecnologias que aumentam o controle do processo de trabalho agrícola e da natureza por atores externos (empresas, bancos, Estado, agências). Outro é uma "centralização estatal" da agricultura, por meio da incorporação das interrelações entre várias instituições e atores por parte do Estado, para a coordenação de conflitos de interesse e decisões coletivas concernentes ao setor e à reprodução econômica destes grupos sociais (Ploeg, 1992).

A modernização capitalista da agricultura teve como elemento dinamizador o processo de "incorporação institucional", baseado nas mudanças tecnológicas gestadas nos países desenvolvidos e difundido aos países subdesenvolvidos através do que ficou conhecido como "Revolução Verde" (adoção de novas técnicas agronômicas e tecnologias, como tratores e mecanização, uso de sementes modificadas, adubos e fertilizantes industriais, agroquímicos em geral e biotecnologias). Profundas alterações nas estruturas sociais rurais dos países periféricos ocorreram em consequência destas mudanças tecnológicas e mercantis.

Nos países "subdesenvolvidos", como no caso do Brasil, a chamada "modernização da agricultura" teve início no período desenvolvimentista do segundo pós-guerra, chegando ao seu auge na década de 1970. Neste período, a dinâmica tecnológica e a expansão dos mercados agrícolas foram institucionalmente induzidas através de políticas de intervenção do Estado, como investimentos na pesquisa aplicada, na assistência técnica e 
extensão rural, e no fornecimento seletivo de crédito subsidiado. Os principais beneficiários, além das indústrias - especialmente as estrangeiras -, foram os grandes agricultores "mais eficientes" e produtivos, excluindo os "ineficientes" - basicamente a chamada "pequena agricultura", de "baixa renda" ou "de subsistência". Dado o caráter intensivo em capital de tal modelo de agricultura, muitas regiões e grande parte dos agricultores, sobretudo os familiares, foram alijados do processo de modernização tecnológica. Apesar do relativo sucesso nos quesitos produção e produtividade, este modelo reproduziu as desigualdades distributivas na propriedade e na renda, gerou êxodo rural, desemprego nos campos e nas cidades, marginalização urbana, exclusão social e econômica, e desarticulação regional dos processos de desenvolvimento econômico.

Já nos países "desenvolvidos", que tiveram seu desenvolvimento agrário em maior ou menor grau - dependendo das especificidades de cada contexto histórico - baseado na agricultura familiar absorvedora de inovação e de progresso técnico (vista como eficiente e competitiva, nesses casos), o problema veio mais tarde, sob a forma de cost-price squeeze e treadmill tecnológico na agricultura ${ }^{8}$. Posteriormente, esses problemas também começaram a emergir nos países "em desenvolvimento", juntando-se aos problemas de saúde dos agricultores e consumidores e aos problemas ambientais, decorrentes do uso de agroquímicos e de técnicas insustentáveis do ponto de vista ecológico. O que veio a contribuir para a geração de uma verdadeira "falha metabólica" na relação sociedade-na-

8 Os conceitos de treadmill (Cochrane, 1979, apud Veiga, 2007) e de squeeze (Ploeg, 2008 e 2006) demonstram que os agricultores modernizados se vêem obrigados a incorporar progresso técnico para se manterem competitivos, ou seja, encontram-se constantemente presos a uma esteira rolante (treadmill) de inovação tecnológica. Isso significa uma necessidade crescente de adição de insumos externos para manter economias de escala, tornando seus custos de produção cada vez mais elevados. Consequentemente, à medida que o progresso técnico é incorporado, e que aumentam as escalas de produção, são reduzidos os preços pagos ao produtor, ou seja, ocorre um estrangulamento (squeeze) na relação custo-preço. 
tureza, jamais vista em tamanha proporção na história da humanidade ${ }^{9}$. Como já alertava Polanyi, na "Idade da Máquina", com seu industrialismo modernizante e a mercantilização dos elementos substantivos da vida, a economia se desenvolve em contradição com a humanidade, com o ambiente natural e com a própria organização produtiva.

Esse paradigma produtivista de dinâmica tecnológica e de inserção concorrencial nos mercados não decorre de um processo espontâneo, mas de um sistema de políticas para a regulação setorial organizado através da intervenção do Estado, das organizações profissionais dos agricultores e das instituições e políticas econômicas. O que veio a conformar novas dinâmicas produtivas ao longo do século XX, baseadas em monoculturas e especialização produtiva, sobretudo a partir do período "fordista" pós-segunda guerra, em que a agricultura foi praticamente "socializada" com o objetivo de se rebaixar o valor da força de trabalho, através da redução do custo de alimentação dos trabalhadores urbanos, permitindo um padrão de acumulação baseado em produção e consumo de massa (Abramovay, 2007).

Hodiernamente, os principais produtos agrícolas têm seus mercados organizados por diversos elos intermediários em cadeias globais de valor, dominadas por capitais agroindustriais e comerciais cada vez mais integrados através das finanças. Essa integração financeira dos capitais também se reflete na crescente concentração dos canais de distribuição varejistas, a exemplo das grandes redes de supermercados (Reardon et al., 2003), constituindo verdadeiros "Impérios Alimentares" (Ploeg, 2008). A questão, todavia, conforme argumenta Steiner (2007), é que os mercados são, ao mesmo tempo, um dispositivo político e uma construção social,

9 Sobre o conceito de "falha metabólica" na relação entre natureza e sociedade humana, derivado originalmente de Marx, ver os desenvolvimentos elaborados por John Bellamy Foster (2005) e Joan Martinez-Alier (2005). 
sendo um de seus fins e justificações o de conduzir as pessoas à satisfação de suas necessidades materiais - no caso, sua própria segurança alimentar. Portanto, os mercados alimentares podem ser considerados "mercados especiais", na medida em que os alimentos - elemento substancial do sustento do homem - também são mercadorias fictícias. A inclusão dos alimentos no mercado capitalista é mais uma expressão de risco à sociedade e à natureza, porque isso inverte a ordem de prioridade entre o meio (o mercado) e o fim (os seres humanos) (Steiner, 2007, p.5; tradução nossa). Ou seja, porque os mercados criam, ao mesmo tempo, as condições estruturais - o alinhamento cognitivo e prático - da produção e da difusão dos medos alimentares (Steiner, 2007, p.14; tradução nossa) ${ }^{10}$. Condições estas coerentes com o projeto político de uma sociedade de mercado, mas não com a liberdade individual numa sociedade complexa, tampouco com a face rural do desenvolvimento.

Por outro lado, olhando o desenvolvimento enquanto processo histórico de mudança social ao longo do tempo, é possível observarmos que a mercantilização - tanto dos bens de produção e consumo como dos mais diversos aspectos materiais e simbólicos da vida social, política e cultural, bem como da relação humana com a natureza - provoca "metamorfoses" no ser social e modifica suas dinâmicas de reprodução. Isto também é evidente na vida rural. De modo que o resultado da integração das populações e do espaço rural ao sistema de mercados no desenvolvimento do capitalismo não implica necessariamente na "desagregação do campesinato" ou na "urbanização total", mas numa série de transformações através de

10 Essa afirmação pode ser respaldada em uma leitura de Polanyi, quando ele define o medo da fome como um motivo econômico apenas na moderna sociedade de mercado: "Pois, em regra, o indivíduo numa sociedade primitiva", ou "nas sociedades que vivem à margem da subsistência", (...) "não se vê ameaçado de inanição, a menos que a comunidade como um todo também não esteja em situação semelhante." (Polanyi, 2000, p.198). 
processos complexos de diferenciação e estratificação socioeconômica, as quais vão modificando suas características tradicionais. Isso se expressa na diversidade e na heterogeneidade das formas sociais rurais, bem como das relações de produção, circulação e consumo instituídas, enquanto processos imersos nas contradições das economias de mercado. ${ }^{11}$

\section{Atores sociais, instituições e desenvolvimento rural: um "duplo movimento" em curso}

Estão em curso expressivas mudanças nas referências analíticas e nas formas de atuação dos estudiosos, dos policy makers e dos atores sociais no que concerne ao desenvolvimento rural. Temas como território, ruralidade e desenvolvimento têm passado por constantes tentativas de atualização e renovação. Isto ocorre não apenas no campo acadêmiCo, mas também no campo político e nas práticas de diferentes grupos sociais. Schneider (2009, p.26) aponta para o fato de que um número crescente de programas governamentais e de agências e organizações nacionais e internacionais, públicas e privadas, vêm operando a partir de referências que tem em comum ideias como: (a) a ruralidade é heterogênea e não circunscrita às atividades agrícolas; (b) os territórios são espaços adequados para se pensar a articulação entre escalas regionais e locais e a globalização; (c) o desenvolvimento precisa levar em conta não apenas questões econômicas, tecnológicas e produtivas, mas também culturais e ambientais; (d) a mudança é um processo lento, que precisa trazer efeitos práticos como melhorar a renda e a qualidade de vida, mas também incidir sobre a mentalidade das pessoas envolvidas e ser capaz de ser assimilado pelas instituições.

11 A propósito das "metamorfoses" da agricultura familiar, ver Plein e Schneider (2003) e Schneider e Niederle (2008); e, a propósito do debate em torno da controvérsia da "urbanização total" (Henri Lefebvre) e do "renascimento do rural" (Bernard Kayser), ver Veiga (2006). 
O processo de globalização, que consolida o "mercado mundial" e aprofunda a reestruturação capitalista, gera um processo combinado de distanciamento e compressão na relação espaço-tempo. Como resultado, promove uma nova divisão internacional e territorial do trabalho, que altera as formas organizacionais das firmas e os processos de produção e circulação de mercadorias em escala global. De tal forma que a reestruturação capitalista também causa impactos nas áreas rurais, tornando-as cada vez mais abertas e interconectadas com as dinâmicas tecnológicas, mercantis e político-institucionais do capitalismo contemporâneo. Isto faz ampliar a dependência do rural em relação a forças externas e paulatinamente reduz a autonomia que historicamente era mantida em relação à sociedade abrangente, promovendo uma notável heterogeneidade social e espacial nas áreas rurais (Marsden, 1999). Quer dizer, o "moinho satânico" toma de assalto todas as esferas da vida social e, o mundo rural, de forma alguma se isenta desta influência. Mas, se é verdade que há um "movimento" de aprofundamento da sociabilidade capitalista e do intercâmbio mercantil na agricultura e no espaço rural, também é certo que isso não ocorre sem contestações e "contramovimentos".

Toda essa complexidade evidencia o fato de que fazer desenvolvimento rural não consiste apenas em adicionar coisas novas a velhas situações estabelecidas (Ploeg et al., 2000). Portanto, não devemos pensar o desenvolvimento apenas como resultado das leis da economia política, da lógica da mercantilização e dos padrões de acumulação de capital, ou mesmo das políticas dos Estados nacionais e das agências multilaterais, mas sim como resultado destes processos em interface com as circunstâncias particulares dos territórios. Neste sentido, podemos afirmar que o desenvolvimento rural - nos (e para além dos) limites da economia de mercado capitalista - é o devir de um projeto político, a ser instituído através da ação deliberada dos atores sociais e das organizações envolvidas, bem como de toda a sociedade. 
Se é verdade que as metamorfoses da ruralidade resultam da reestruturação capitalista e de ações e políticas do Estado e das grandes corporações, também é certo que os atores locais não acatam essas mudanças passivamente. A interação dialética entre os agricultores e os modelos de agricultura e de estrutura econômica hegemônicos produz padrões diferenciados e heterogêneos de reprodução social e de dinâmicas territoriais. Essa heterogeneidade resulta, sobretudo, da capacidade que os atores têm de processar a experiência social e influenciar a mudança institucional nos territórios. Na visão de Long e Ploeg (2009), isso ocorre porque, embora os processos externos de intervenção sejam muitas vezes instituídos fora dos campos imediatos de interação dos agricultores, nas práticas cotidianas esses processos são ressignificados pelos atores e mediados pelas instituições locais. Ao exercerem sua capacidade de agência, os atores participam ativamente (embora nem sempre no nível de consciência discursiva) na construção de seus próprios mundos sociais, ainda que, como Marx (1962, p. 252) nos previne, as circunstâncias que eles encontram não sejam simplesmente fruto de sua própria escolha. (Long \& Ploeg, 2009, p.7).

A chave para a compreensão dessa relação dialética entre os atores e as estruturas em uma interação complexa, que está na origem dos processos de desenvolvimento, é a noção de "agência". ${ }^{12}$ As mudanças estruturais são resultado justamente das interações entre os atores sociais. Os atores são socialmente constituídos e, assim sendo, são também agentes da mudança social. Os indivíduos não são simplesmente constrangidos, passivamen-

12 O problema entre estrutura e agência nas ciências sociais é um assunto bastante complexo, que tem sido amplamente discutido pela literatura. No que concerne a este trabalho, vale destacar que a concepção desposada por Long e Ploeg (2009) é diretamente tributária da "Teoria da Estruturação" do sociólogo Anthony Giddens. Críticas a essa perspectiva podem ser encontradas em Hodgson (2004), que propõe uma análise alternativa da questão através do conceito de "reconstitutive downward causation". Este conceito está ligado ao papel de mediação exercido pelas instituições e pelos hábitos mentais na relação entre estruturas e indivíduos. É uma perspectiva mais condizente com a análise institucional de Polanyi, autor diretamente ligado ao "velho institucionalismo" de Veblen, no qual também se inscreve o institucionalismo-evolucionário de Hodgson. 
te, por estruturas institucionais insensíveis a mudanças no curso da história: eles também são capazes de alterá-las. Do complexo e contínuo processo de interação entre os atores e as estruturas em que estão imersos, resulta, portanto, uma diversidade de inovações sociotécnicas e institucionais; ou seja, de práticas locais de trabalho e produção e de arranjos sociopolíticos territorialmente institucionalizados, adaptados pelos agricultores às suas possibilidades de reprodução socioeconômica. De acordo com as experiências dos atores envolvidos, suas perspectivas, valores, interesses e procedimentos, eles podem resistir às tendências tecnológicas e institucionais hegemônicas, intervindo e alterando diretamente os processos de trabalho e produção e, assim, os próprios espaços de produção e vida. Para Ploeg (2007), esses fenômenos de resistência são "mais comuns do que nós normalmente assumimos, percebemos, ou estamos dispostos a admitir". Eles estão imersos nas práticas diversas e heterogêneas dos agricultores familiares e camponeses, os quais buscam defender e criar autonomia e melhores condições de vida como respostas locais para problemas globais. Tais fenômenos efetivamente representam aquilo que Polanyi (2000) chama de "contramovimentos".

Neste sentido, é necessário desconstruir tanto a ideia do agricultor como um empresário rural especializado e integrado aos mercados de commodities, como ideal a ser seguido e copiado, quanto aquela do camponês autárquico, que vive e produz apenas para a subsistência. $\mathrm{O}$ desafio consiste em (re)construir processos que promovam diversificação produtiva e tecnológica, economias de escopo, bem como mecanismos de troca e distribuição enraizados em relações sociais baseadas em princípios de reciprocidade e redistribuição (Polanyi, 2000). Diante de tal quadro, na medida em que a ação dos agricultores desencadeia formas de resistência à dependência imposta pelos "Impérios Alimentares", além da criação de autonomia, esta ação tem potencial para dinamizar processos de produção e de trabalho mais sustentáveis ecologicamente na agricultura, em termos de coprodução (encontro, interação e transformação mútua do homem com a natureza) (Ploeg, 2006). 
Neste processo, outros mecanismos podem ser acionados. Quando confrontados com os mercados, os agricultores podem criar "espaços de manobra", que deslocam a atividade econômica da relação de treadmill tecnológico e de cost-price squeeze, aumentando a agregação de valor, ou seja, os ganhos substantivos, bem como a competitividade territorial ligada ao dinamismo do espaço rural (Ploeg, 2006, 2007, 2008). Um exemplo proeminente são as iniciativas de agregação de valor e enraizamento das relações sociais, onde as economias dos territórios são integradas por meio de iniciativas como: "cadeias alimentares curtas", agroindústrias familiares, redes de associação e cooperação (comércio justo, certificação solidária, redes de cooperativas locais) e mecanismos de redistribuição (Gutmann, 2007). Outro aspecto importante que pode ser considerado através da análise de Polanyi, diz respeito às relações entre produtores e consumidores e ao papel das políticas públicas e da atuação do Estado. Segundo Polanyi, distintas "formas de integração" podem coexistir, mesmo em uma sociedade de mercado, em uma economia capitalista. Através de processos politicamente orientados, é possível a criação de padrões de troca e distribuição mais autônomos, constituídos sobre relações de reciprocidade, de troca socialmente regulada e de redistribuição, através do movimento de bens e serviços em direção a centros determinados, e de seu retorno aos consumidores por meio de mecanismos institucionalizados em dispositivos coletivos e públicos, articulados entre instâncias do estado e da sociedade civil. ${ }^{13}$

13 Para além das políticas agrícolas tradicionais (crédito, preços, seguros, etc.), temos no Brasil exemplos de uma nova geração de políticas relacionadas ao desenvolvimento rural, como a criação de "mercados institucionais" para a agricultura familiar através do Programa de Aquisição de Alimentos (PAA) e o Programa Nacional de Alimentação Escolar (PNAE). O PAA é um instrumento de política pública instituído pelo artigo 19 da Lei no. 10.696, de 2 de julho de 2003, e regulamentado pelo Decreto no. 6.447, de 07 de maio de 2008, alterado pelo Decreto no 6.959, de 15 de setembro de 2009. O PNAE foi criado em 1955 pelo decreto n.37.106, e em 2009, através da Lei 11.947/2009, ficou instituído que pelo menos 30\% dos alimentos devem ser adquiridos da agricultura familiar organizada em associações, cooperativas, ou grupos informais. No Brasil já contamos com estudos influenciados pela perspectiva de Polanyi que analisam a relação entre o Estado e os atores e organizações da sociedade civil na construção e operacionalização desse tipo de política pública e avaliam preliminarmente alguns de seus resultados. Ver Guareschi (2010), Müller (2007) e Triches (2010). 
A efetividade dessas possibilidades não ocorrerá apenas através de mecanismos de mercado. Ela resulta de processos de mudança das estruturas econômicas e políticas que estão na base do ordenamento social. Estes processos dizem respeito às formas como são organizadas as relações sociais de troca e distribuição, a divisão do trabalho, as relações de propriedade, a separação entre consumidores e produtores e o modo de atuação do Estado. Nos termos de Polanyi (1977), tais processos dizem respeito à organização social do poder apropriacional, a qual localiza a matriz institucional que ordena tanto as relações econômicas entre os homens como os direitos e obrigações que sancionam os movimentos situacionais de bens e pessoas articulados com os meios natural e social. Em outras palavras, o desenvolvimento rural precisa ser construído através da ação coletiva, expressa por meio da política. De acordo com o institucionalismo de Polanyi (2000), nas economias mercantil-capitalistas, a institucionalização deste tipo de processo depende da capacidade dos atores sociais de produzirem "contramovimentos" para a autoproteção do tecido humano, da natureza externa ao homem e da própria organização do processo econômico.

\section{Considerações finais}

Neste texto, propusemos uma recuperação das principais contribuições de Karl Polanyi, cotejando-as com o tema do desenvolvimento nos dias atuais. A fim de explorar as potencialidades dessas proposições para os debates mais específicos sobre desenvolvimento rural no caso do Brasil, alguns comentários finais são necessários.

Conforme já indicado em outro trabalho (Schneider, 2010), a discussão corrente sobre o tema do desenvolvimento rural no Brasil desde os anos 1990 vem sendo fortemente influenciada por ações de caráter 
normativo, pois é tributária das políticas públicas e da intervenção do Estado. Este fato reflete as novas concepções e aportes adotados pelos policy makers, juntamente com intelectuais acadêmicos e mediadores, que elaboram propostas e acabam influenciando e conduzindo os rumos dessas ações e debates, mais do que as demandas dos próprios atores e organizações ligadas ao meio rural. Outros fatores também influem nos rumos da discussão, como a legitimação política da categoria agricultura familiar e as dificuldades em torno da realização da reforma agrária; a forma como as questões ambientais e as relacionadas à sustentabilidade foram incorporadas ao tema mais amplo do desenvolvimento rural; e a legitimidade, mas também as tensões, de natureza política e ideológica expressas na polarização (ou mesmo maniqueísmo) entre os defensores da agricultura familiar vs. os do agronegócio. O que se manifesta institucionalmente na existência de dois ministérios ligados à agricultura no Brasil (MAPA e MDA), cujos projetos políticos e as formas de atuação são marcados por uma relação de constante tensão.

Neste mesmo trabalho supracitado, também foram mapeadas e comparadas, ainda que de maneira deveras resumida, as principais referências teóricas mobilizadas pelos estudiosos do desenvolvimento rural no Brasil. Foram mencionadas algumas convergências entre elas, mas o que ficou constatado é que há pouca coincidência, tanto em relação às perspectivas e tendências para o meio rural quanto no que se refere às estratégias a serem seguidas. Daí se esbarra em uma grande dificuldade na elaboração de referências teóricas, metodológicas e empíricas comuns, dificuldade esta relacionada justamente ao fato de não haver uma agenda temática própria, que não seja tributária das formulações do Estado, mediadores e outros organismos.

É neste aspecto que a abordagem de Polanyi, com a característica plural e interdisciplinar das abordagens institucionalistas (Conceição, 2002), 
pode oferecer grande contribuição e pavimentar caminhos promissores. Conforme tentamos demonstrar ao longo deste trabalho, sua abordagem é muito oportuna e adequada para uma perspectiva analítica orientada ao papel dos atores e das instituições nos processos de mudança social, como aqueles caracterizáveis como de "desenvolvimento rural". Isto porque possui uma visão que rompe com o problema entre estrutura e agência e apresenta um esquema de análise que integra elementos tecnológicos, ecológicos e culturais, num framework capaz de apreender de maneira dinâmica e histórica as interrelações entre estado, mercados e sociedade civil.

\section{The Contribution of Karl Polanyi for the rural development sociology}

\section{Abstract}

The essay deals with the importance of the rediscovery of Karl Polanyi's thinking and of his criticism of the "market society" in resuming (rural) development studies and debates. Following an overall presentation of Polanyi's theoretical and analytical framework, we look for using his concepts to interpret the commoditization dynamics of the rural livelihoods and the social forms of labor and production in the rural space, as well as the commoditization of the agri-food systems in the contemporary capitalism. Based on these statements, we reflect about the role of social actors and institutions in the processes of social change at large and of rural development in particular. And, finally, we propose some potentialities of this approach for the rural development studies in Brazil.

Key-words: Karl Polanyi. Commoditization. Institutions. Social actors. Rural development.

\section{Referências}

ABRAMOVAY, Ricardo. Paradigmas do capitalismo agrário em questão. 3ed. São Paulo: Edusp, 2007.ADAMAN, Fikret; MADRA, Yahya M. Theorizing the 
"Third Sphere": a critique of the persistence of the "Economistic Fallacy". Journal of Economic Issues, v.36, no.4, dec., 2002.

ARNSPERGER, Christian; VAROUFAKIS, Yanis. What is Neoclassical Economics? The three axioms responsible for its theoretical oeuvre, practical irrelevance and, thus, discursive power. Post-austistic Economics Review, n.38, p.2-12, 2006.

ASSOCIAÇÃO KEYNESIANA BRASILEIRA. Dossiê da Crise. Novembro de 2008. Disponível em: http://www.ppge.ufrgs.br/akb/dossie-crise.pdf. Acesso em: 25/12/2009.

. Dossiê da Crise II. Agosto de 2010. Disponível em: http://www.ppge.

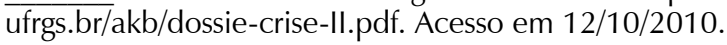

BEBBINGTON, Anthony. Development: rural development strategies. In: SMELSER, N.L.; BALTES, P.B. (Eds). International Encyclopedia of Social \& Behavioral Sciences. Oxford: Elsevier, 2001. p. 3578-3583.

BECKERT, Jens. The Great Transformation of Embeddedness. Karl Polanyi and the New Economic Sociology. Max Planck Institute for the Studies of Societies, Discussion Paper, 2007.

BLOCK, Fred. Karl Polanyi and the writing of The Great Transformation. Theory and Society, n.00. p. 1-32, 2003.

BRESSER-PEREIRA, Luiz C. O Novo Desenvolvimentismo e a Ortodoxia Convencional. São Paulo em Perspectiva, v.20, n.3, p.5-24, jul.-set. 2006.

BUGRA, Ayse; AGARTAN, Kaan. (org.) Reading Karl Polanyi for the TwentyFirst Century: Market Economy as a Political Project. Oxford: Palgrave Macmillan, 2007.

BUGRA, Ayse. Polanyi's concept of double movement and politics in the contemporary market society. In: BUGRA, A.; AGARTAN, K. (org.). Reading Karl Polanyi for the Twenty-First Century: Market Economy as a Political Project. Oxford: Palgrave Macmillan, 2007.

BURAWOY, Michael. For a sociological marxism: the complementary convergence of Antonio Gramsci and Karl Polanyi. Politics Society, v.31, p. 93-168, 2003.

CHANG, Ha-Joon. Maus samaritanos: o mito do livre-comércio e a história secreta do capitalismo. Rio de Janeiro: Elsevier, 2009.

CONCEIÇÃO, Octávio A. C. A Contribuição das Abordagens Institucionalistas para a Constituição de uma Teoria Econômica das Instituições. Ensaios FEE, Porto Alegre, v.23, n.1, p.77-106, 2002.

DUPAS, Gilberto. O Mito do Progresso. São Paulo: Editora da UNESP, 2006. 
ESCOBAR, Arturo. Beyond the search for a paradigm? Post-development and beyond. Development, v.43, n.4, pp.11-14, 2000.

FOSTER, John Bellamy. A ecologia de Marx: materialismo e natureza. Rio de Janeiro: Civilização Brasileira, 2005.

FRIEDMANN, Harriet. The political economy of food: a global crisis. In: HarrissWhite, Barbara (ed.). Food. Oxford: Basil Blackwell, 1993.

GOODMAN, David; SORJ, Bernardo; WILKINSON, John. Da lavoura às biotecnologias. Agricultura e indústria no sistema internacional. Rio de Janeiro: Campus, 1990.

GRANOVETTER, Mark. Economic Action and Social Structure: The Problem of Embeddedness. American Journal of Sociology, v.91, n.3, pp.481-510, 1985.

GUARESCHI, Amanda. A operacionalização da Política de Segurança Alimentar: O caso do Programa de Aquisição de Alimentos em Tenente Portela, RS. Porto Alegre: PGDR/UFRGS, 2010. (Dissertação de Mestrado em Desenvolvimento Rural).

GUTMANN, Julie. The Polanyian Way? Voluntary Food Labels as Neoliberal Governance. Antipode, v.39, n.3, pp.456-478, jun.2007.

HARVEY, David. A Brief History of Neoliberalism. New York: Oxford University Press, 2005.

HAYEK, Friedrich A. O caminho da servidão. 4ed. Rio de Janeiro: Expressão e Cultura, 1987.

HODGSON, Geoffrey M. The Evolution of Institutional Economics. Agency, structure and Darwinism in American Institutionalism. London and New York: Routledge, 2004.

JESSOP, Bob. Knowledge as a fictitious commodity: insights and limits of a Polanyian perspective. In: BUGRA, A.; AGARTAN, K. (org.). Reading Karl Polanyi for the Twenty-First Century: Market Economy as a Political Project. Oxford: Palgrave Macmillan, 2007.

JESSOP, Bob. State Power. A Strategic-Relational Approach. Cambridge: Polity Press, $2007 \mathrm{~b}$.

KURZ, Robert. O colapso da modernização. São Paulo: Paz e Terra, 1992.

LACHER, Hannes. The slight transformation: contesting the legacy of Karl Polanyi. In: BUGRA, A.; AGARTAN, K. (org.). Reading Karl Polanyi for the Twenty-First Century: Market Economy as a Political Project. Oxford: Palgrave Macmillan, 2007. 
LONG, Norman; PLOEG, Jan Douwe van der. Heterogeneidade, ator e estrutura: para a reconstituição do conceito de estrutura. In: BOOTH, D. (ed.) Rethinking Social Development: theory, research and practice. England, Longman, 1994, p. 62-90. PGDR/UFRGS: Porto Alegre, 2009. (Versão para circulação interna).

LONG, Norman. Sociología del Desarollo: Una Perspectiva Centrada en el Actor. México: CIESA, 2007.

LOPES, José Sergio Leite. Sobre um debate da antropologia econômica: a economia política de Karl Polanyi. Revista do Centro Latino Americano de Ciências Sociais, ano 14, n.3-4, julho-dezembro, Rio de Janeiro, 1971.

MACHADO, Nuno Miguel Cardoso. Sociedade vs. Mercado - Notas sobre o Pensamento Económico de Karl Polanyi. Lisboa: Universidade Técnica de Lisboa, 2009. 204p. (Tese de Doutorado em Sociologia Económica e das Organizações).

MARSDEN, Terry. Rural futures: the consumption countryside and its regulation. Sociologia Ruralis, vol.39, n.4, pp.501-520, 1999.

MARTINEZ-ALIER, Joan. Social metabolism and ecological distribution conflicts. Australian New Zealand Society for Ecological Economics, Massey University, Palmerston North, 11-13 Dec. 2005.

MAUCOURANT, Jérôme. Avez-vous lu Polanyi? Paris: La Dispute, 2005.

MCMICHAEL, Philip. The power of food. Agriculture and Human Values, n.17, p.21-33, 2000.

MENDELL, Marguerite. Karl Polanyi and instituted process of economic democratization. Paper presented for "Polanyian Perspectives on Instituted Economic Processes, Development and Transformation" Conference. ESRC, Center for Research on Innovation and Competition. University of Manchester: Oct. 23-25, 2003.

MOLINA, José Luis. Manual de antropología económica. Bogotá: UAB, 2004.

MÜLLER, Ana Luiza. A construção das políticas públicas para a agricultura familiar no Brasil: o caso do Programa de Aquisição de Alimentos. 2007. 128 p. Dissertação (Mestrado em Desenvolvimento Rural) - PGDR/UFRGS, Porto Alegre.

OLIVEIRA, Francisco de. Os direitos do antivalor: a economia política da hegemonia imperfeita. Petrópolis: Vozes, 1998.

PEARSON, Harry. Editor's Introduction. In: POLANYI, Karl. The livelihood of man. London: Academic Press, 1977. 
PLEIN, Clério; SCHNEIDER, Sergio. Agricultura familiar e mercantilização. In: CASTILHO, Mara Lucy; RAMOS, José Maria (Ed.). Agronegócio e Desenvolvimento Sustentável. Francisco Beltrão: UNIOESTE, 2003.

PLOEG, J.D Van der. O modo de produção camponês revisitado. In: SCHNEIDER, S. (Org). A diversidade da agricultura familiar. Porto Alegre: Editora da UFRGS, 2006. (Série Estudos Rurais).

PLOEG, J.D Van der. Resistance of the third kind and the construction of susteintability. Paper presented to ESRS Conference, Wageningen, 23 of August, 2007. Disponível em: www.jandouwevanderploeg.com. Acesso em: 21 dez. 2008.

PLOEG, J.D Van der. Camponeses e Impérios Alimentares. Lutas por autonomia e sustentabilidade na era da globalização. Porto Alegre: Editora da UFRGS, 2008. (Série Estudos Rurais).

PLOEG, J.D Van der et al. Rural development: from practices and policies towards theory. Sociologia Ruralis, v.40, n.4, pp.391-408, october 2000.

POLANYI, K. A grande transformação. 2ed. Rio de Janeiro: Elsevier, 2000.

POLANYI, K. A nossa obsoleta mentalidade mercantil. Revista Trimestral de História das Idéias, n.1, pp.7-20. Porto (Portugal), 1977a.

POLANYI, K. The livelihood of man. London: Academic Press, 1977b.

POLANYI, K. La economía como actividad institucionalizada. In: POLANYI, Karl; ARENSBERG, Conrad M.; PEARSON, Harry W. (Ed.). Comercio y Mercado en los Imperios Antiguos. Capítulo XIII, p.289-316. Barcelona: Labor Universitaria, 1976.

REARDON, T., TIMMER, C. P., BARRETT, C. B.; BERDEGUE, J. A. The rise of supermarkets in Africa, Asia, and Latin America. American Journal of Agricultural Economics, 85(5), 1140-1146, 2003.

RIST, Gilbert. Development as a buzzword. Development in practice, v.17, n.4-5, August 2007.

SACHS, Ignacy. Entre Polanyi e Von Hayek. Revista de Economia Política, v.12, n.2 (46), abr.-jun., 1992.

SANCHÉZ, A. L. La crítica de la economía de mercado en Karl Polanyi: el análisis institucional como pensamiento para la acción. REIS, 86/99, p. 27-54, 2008.

SCHNEIDER, S. A abordagem territorial do desenvolvimento rural e suas articulações externas. Sociologias, Porto Alegre, a.6, n.11, p.88-125, jan-jun, 2004. 
SCHNEIDER, S. Situando o desenvolvimento rural no Brasil: o contexto e as questões em debate. Revista de Economia Política, v. 30, n.3, p.511-531, JulSet/2010.

SCHNEIDER, S.; NIEDERLE, P. A. Agricultura familiar e teoria social: a diversidade das formas familiares de produção na agricultura. In: FALEIRO, F.G. e FARIAS NETO, A.L. (ed.) SAVANAS: desafios e estratégias para o equilíbrio entre sociedade, agronegócio e recursos naturais.. Planaltina-DF, Embrapa Cerrados: 2008. p. 989-1014.

SCHNEIDER, S.; SILVA, M.K.; MARQUES, P. E. M. (Org.) Políticas Públicas e Participação Social no Brasil Rural. 2ed. Porto Alegre: Editora da UFRGS, 2009. (Série Estudos Rurais)

SEN, Amartya K. Desenvolvimento como Liberdade. São Paulo: Companhia das Letras, 2000.

STEINER, Philippe. Les marchés agroalimentaires sont-ils des "marchés spéciaux"? Première version présenté au colloque "Les marchés agroalimentaires", mars 2006, organisé par Fabrice Dreyfus à l'INRA: Montpellier, 2007.

STGLITZ, Joseph E. Globalization and its Discontents. New York: W.W. Norton \& Co., 2002.

THOMAS, Alain. Development as a practice in a liberal capitalist world. Journal of International Development, n.12, p.773-787, 2000.

TRICHES, Rozane M. Reconectando a produção ao consumo: a aquisição de gêneros alimentícios da agricultura familiar para o Programa de Alimentação Escolar. 2010. 296 p. Tese (Doutorado em Desenvolvimento Rural) - PGDR/UFRGS, Porto Alegre.

VEIGA, José Eli da. Nascimento de outra ruralidade. Estudos Avançados, v.20, n.57, p. 333-353, 2006.

VEIGA, José Eli da. O desenvolvimento agrícola. Uma abordagem histórica. 3ed. São Paulo: Edusp, 2007.

Recebido: 16/02/2011

Aceite final: 05/05/2011 